Revista Internacional de Apoyo a la Inclusión, Logopedia, Sociedad y Multiculturalidad.

Volumen 7, Número 1, enero 2021, ISSN: 2387-0907. DOI: https://dx.doi.org/10.17561/riai.v7.n1.6

\title{
El proceso lector: implicaciones y contribuciones de la neurociencia y la neuroeducación
}

The reading process: implications and contributions of neuroscience and neuroeducation

Der Leseprozess: implikationen und beiträge der neurowissenschaften und der neurowissenschaftlichen ausbildung

Le processus de lecture: implications et contributions des neurosciences et de l'enseignement des neurosciences

O Processo de Leitura: implicações e contribuições da educação em neurociência e neurociência Il processo di lettura: implicazioni e contributi delle neuroscienze e dell'educazione alle neuroscienze Процесс чтения: последствия и вклад неврологии и неврологического образования 読書プロセス: 神経科学・神経科学教育の含意と貢献 阅读过程: 神经科学和神经科学教育的意义和贡献。

Juan José Fernández Domínguez

Universidad de Jaén (España) jjfd0002@red.ujaen.es

Fecha recepción: 1/10/2020

Páginas 92-103

Fecha aceptación: 29/12/2020

\section{Resumen.}

El presente artículo, sumerge al lector en el análisis descriptivo de las principales características del comportamiento, funcionalidad y actividad cerebral humana durante la lectura, gracias a los conocimientos ofrecidos por la neurociencia. Se inicia dando a conocer los aspectos más relevantes de la neurociencia, tratando seguidamente, la implicación de la misma en el ámbito educativo mediante la neuroeducación y la neurodidáctica. Asimismo, se expone detalladamente el proceso de aprendizaje lector, vías de acceso y procesos cognitivos involucrados. Se continúa, con la exposición de las áreas lectoras, y en última instancia, se explica cómo se produce la lectura. A modo de conclusión, se presentan diversas implicaciones de la neurociencia en el tratamiento educativo de la enseñanza y aprendizaje de la lectura. En definitiva, se refleja la forma en la que la neurociencia pone de manifiesto las posibilidades del cerebro humano en las tareas lectoras, y la capacidad de esta ciencia para trabajar junto a las ciencias educativas y así, mejorar diversos procesos de aprendizaje.

Palabras clave: neurociencia; neuroeducación; cerebro; aprendizaje; lectura

\section{Abstract.}

This article immerses the reader in the descriptive analysis of the main characteristics of human behavior, functionality and brain activity during reading, thanks to the knowledge offered by neuroscience. It begins by publicizing the most relevant aspects of neuroscience, then dealing with its involvement in the educational field through 
neuroeducation and neurodidactics. Likewise, the reader learning process, access routes and cognitive processes involved are exposed in detail. It continues, with the exhibition of the reading areas, and ultimately, it explains how reading occurs. By way of conclusion, various implications of neuroscience in the educational treatment of the teaching and learning of reading are presented. In short, it reflects the way in which neuroscience reveals the possibilities of the human brain in reading tasks, and the ability of this science to work together with educational sciences and thus improve various learning processes.

Keywords: neuroscience; neuroeducation; brain; learning; reading

\section{1.-Introducción.}

El tema que se aborda parte desde la neurociencia, siendo esta, el eje vertebrador a partir de la cual se profundizará en uno de los pilares esenciales en la formación de una persona, la educación. Así pues, posteriormente, nos ocupamos de dar una visión actualizada a dicho tópico, donde se vincula tanto la neurociencia como la enseñanza, surgiendo así, un nuevo término, con el que podremos comprender el proceso de aprendizaje de la lectura.

Dicho esto, el principal objetivo que este artículo pretende alcanzar, es analizar y describir exhaustivamente las características primordiales del funcionamiento, comportamiento y actividad del cerebro humano durante la lectura, a través de los saberes aportados por la neurociencia. De igual forma, es importante que atendamos también a la consecución de otros objetivos más específicos. En consecuencia, en primer lugar, debemos conocer los aspectos más relevantes de la neurociencia como disciplina científica. En segundo lugar, entender la implicación de la neurociencia en la educación. En tercer lugar, dar a conocer el proceso de aprendizaje lector y los elementos que lo conforman. En cuarto lugar, determinar el funcionamiento y la organización de las áreas especializadas en la lectura. En último lugar, visualizar las implicaciones de la neurociencia en el tratamiento didáctico de la lectura.

Por otra parte, en cuanto a la metodología empleada, es la propia de una revisión teórica sobre las aportaciones de la neurociencia en el proceso de aprendizaje de la lectura. En virtud de ello, se ha llevado a cabo una búsqueda y una recopilación extensa acerca del tema objeto de estudio. En relación al proceso de búsqueda bibliográfica que hemos acometido, cabe resaltar que seleccionamos algunas bases y fuentes de datos fiables, siendo estas: "Google académico", "Wos (Web of Science)", "Scopus", "Redalyc", "ScienceDirect", "Scielo", "Eric" y "Dialnet". En las mismas, se introdujeron palabras claves con el fin de obtener una información más acertada y válida. Algunas de estas fueron: neurociencia, neuroeducación, lectura y neurociencia o cerebro y lectura. Además, se han diferenciado dos tipos de búsquedas, una focalizada en la contextualización del trabajo y otra para la revisión de trabajos ya elaborados.

Seguidamente, debido a la gran cantidad de información encontrada, se han aplicado unos criterios de inclusión para la elección de los artículos que iban a ser revisados, entre los que destacan: prioridad de fuentes académicas seguras, información 
relativamente actual, de cierto carácter educativo y de habla inglesa, española 0 francesa.

\section{2.-Marco teórico.}

\section{1.-Concepto de neurociencia y neuroeducación.}

En primer lugar, abordamos el término de neurociencia desde la perspectiva de diferentes autores. Las definiciones que se aportan son relativamente actuales e emiten información relevante acerca de esta terminología. Cabe destacar, que se han propuesto muchas definiciones para este término, y que a día de hoy no existe una definición única, aunque si es cierto, que se utilizan varias para dar significado al respecto. Por una parte, Blakemore y Frith (2011) sostienen, que el término de neurociencia es un tipo de paraguas que alberga diferentes conocimientos, y en el que se reúnen disciplinas como la física, la medicina, la biología o la psicología entre otras, con la meta de conocer tanto la función, el desarrollo y la estructura del cerebro, así como el funcionamiento de las neuronas y la patología del sistema nervioso, para poder conocer las bases biológicas que sustentan la conducta humana. De este modo, cabe la posibilidad de establecer una correlación entre las funciones cognitivas y los comportamientos del ser humano, desarrollando así un nuevo estilo de comprender la mente. Por otra parte, Mora y Sanguinetti (2004) apuestan por entender la neurociencia como una disciplina encargada de estudiar la estructura, función, desarrollo, patología y farmacología del sistema nervioso (p. 75). En cuanto al concepto de neuroeducación, guarda una estrecha relación con el de neurociencia. Igualmente, pese a esta conexión, no todo lo relativo a la neurociencia tiene aplicabilidad al campo educativo. Por esto mismo, es el docente quien tiene que distinguir entre aquello que es significativo y realista para aplicar en la práctica docente y lo que son, meramente, opiniones sin fundamento alguno. Centrándonos ahora sí en el concepto de neuroeducación, esta es considerada una disciplina aún en construcción, que se encarga de la optimización del proceso de aprendizaje y enseñanza, teniendo como sustento el desarrollo cerebral. De esta forma, la neuroeducación está capacitada para sacar provecho a diferentes imágenes cerebrales con el fin de mejorar las técnicas de enseñanza y adaptar las mismas a cada cerebro del estudiante. Igualmente, esta disciplina pretende utilizar los conocimientos basados en las imágenes neurales y/o cerebrales, y trasladarlos a los agentes educacionales, para así, dar prueba de la forma en la que el cerebro del estudiante realiza interacciones con el entorno en el que se lleva a cabo el proceso de enseñanza y aprendizaje (Hernández y De Barros, 2015).

En resumen, debemos entender la neurociencia y consigo, a la neuroeducación como una manera de saber más extensa sobre todo lo que sucede en el cerebro. Es decir, cómo aprende, como procesa, conserva, registra y evoca la información, para que, partiendo del conocimiento cerebral, se pueda extrapolar al aula, una amplia diversidad de optimizaciones de experiencias y propuestas de aprendizaje. 


\section{2.-Metas de la neurociencia en la educación.}

A continuación, se procede a explicar los objetivos que la neurociencia pretende alcanzar en el ámbito educativo. Esta ciencia, se caracteriza pretende visualizar las funciones del cerebro, teniendo esto, un alto beneficio para entender una amplia gama de procesos, quehaceres, trastornos o dificultades que poseen los estudiantes. Por una parte, Mendoza, Murillo y Maldonado (2019), entienden que para afrontar con éxito las aportaciones de la neurociencia en la educación, se necesita un tipo de comportamiento docente que sea, ante todo, emocionalmente inteligente, y que esté capacitado para la búsqueda de otras posibilidades didácticas que antecedan a la neurociencia, considerándola, como un instrumento de carácter científico y de investigación. Por otra parte, se sigue confirmando el innegable impacto de la neurociencia en el proceso de aprendizaje. De ahí, que el llevar a cabo en el aula estrategias didácticas y metodológicas, en relación con los resultados científicos provenientes de estudios neurocientíficos, repercute de manera positiva en los efectos de un aprendizaje significativo real, el cual, optimiza el propio proceso de enseñanza y aprendizaje. Dado que la neurociencia tiene un interés particular en cómo las actividades del cerebro guardan relación con la conducta y aprendizaje de la persona, es fundamental que se emprenda necesariamente un diálogo entre neurocientíficos y docentes, con el propósito de sacar a la luz otras muchas bondades que esconde el cerebro humano dentro del repertorio de respuestas cognitivas que acontecen en la enseñanza y aprendizaje del discente (Puebla y Paz, 2011).

En definitiva, podemos afirmar que cada cerebro es irrepetible y singular, y por esto, las neurociencias demuestran al mundo educativo cuál es el recorrido que debe seguir la pedagogía de hoy en día.

\section{3.-Neurodidáctica.}

Nuestro propósito aquí, es reflejar algunas ideas que manifiestan el modo de hacer didáctica bajo los saberes de la neurociencia. Esto es, lo que anteriormente denominábamos como neuroeducación, será tratada desde las posibilidades que arrojan algunos autores de esta ciencia para hacer didáctica, surgiendo así lo que se conoce como neurodidáctica o didáctica de la neurociencia.

Siguiendo esta línea, Hruby y Goswami (2011), consideran que, desde el punto de vista de la neurociencia, el aprendizaje es un factor interesante durante la etapa escolar, debido a que en este momento, el cerebro desarrolla múltiples conexiones que con posterioridad se convertirán en redes de conocimiento, dando lugar a la memoria. Por ello, el aprendizaje de un nuevo conocimiento permite la producción de neuronas y enlaces detríticos, creándose una red de neuronas más compleja y grande. En tal caso, el aprendizaje visto desde la neurociencia, supone, sobre todo, cambios en la conectividad de las neuronas, alteración de la liberación de neurotransmisores, así como el fortalecimiento o eliminación de neuronas debido a la experiencia y al aprendizaje.

En suma, Paniagua (2013) concluye, que la neurodidáctica es una variante de la pedagogía sustentada en la neurociencia, fundamentada en la aplicación de 
conocimientos sobre el funcionamiento del cerebro y en cómo los procesos neuronales intervienen en el aprendizaje para auxiliar a que este sea más óptimo. Su finalidad consiste en apoyar las estrategias metodológicas y didácticas ya existentes, para promover un desarrollo cerebral mayor en términos que los educadores puedan comprender e interpretar, ya que, sin esto último, su puesta en marcha sería imposible.

\section{3.-El proceso de aprendizaje de la lectura.}

\section{1.-Procesos cognitivos implicados en la lectura.}

A continuación, nos orientamos a exponer aquellos procesos cognitivos que entran en juego durante la actividad lectora. Estas habilidades y procesos son numerosos, y destacan: los procesos perceptivo-visuales, los procesos fonológicos, las habilidades de conciencia fonológica, las habilidades de memoria operativa fonológica, las habilidades de entrada al léxico, los procesos de automatización, los procesos morfológicos y por último, los procesos prosódicos (Defior, Serrano y Gutiérrez, 2015). A propósito de lo que estamos tratando, cabe decir, que la lectura es una habilidad que se adquiere por medio de un gran esfuerzo y por tanto, de mucho tiempo dedicado a su práctica. Leer, es una actividad principalmente fonológica, pero también es una tarea que trabaja la percepción visual.

De igual modo, para entender esta habilidad interesa exponer los procesos y habilidades que interceden en ella. En primer lugar, en cuanto a los procesos perceptivos y visuales, destacamos que la lectura siempre parte de una entrada visual. Además, el reconocimiento de las letras es clave para predecir el aprendizaje lector en los sistemas alfabéticos (Caravolas et al., 2012). En segundo lugar, en lo relativo a los procesos fonológicos, es de resaltar, la relación entre la adquisición de la lectura y la escritura, y tres áreas del procesamiento fonológico, siendo las siguientes: la memoria a corto plazo verbal, la conciencia fonológica y el léxico fonológico. La primera habilidad es implícita, la segunda es explícita y la última, es implícita (Defior y Serrano, 2011). En tercer lugar, las habilidades relativas a la conciencia fonológica, se refieren a aquellas que tienen como fin, indicar el conocimiento que cada persona tiene explícito acerca de los sonidos de su lengua. En este sentido, consiste en la capacidad para segmentar, identificar o fusionar de manera intencionada las sílabas y fonemas de una palabra. Dentro de esta habilidad, existen distintos niveles, entre los que se encuentra, la conciencia léxica, la rima, la silábica, la intrasilábica y la fonémica (Defior, Justicia y Martos, 1998).

En cuarto lugar, las habilidades de memoria operativa fonológica, apuntan a la capacidad de codificar una minúscula cantidad de información verbal, para posteriormente acumularla y mantenerla de manera temporal utilizando un sistema de representación sonora, al mismo tiempo que se va procesando nueva información (Gutiérrez, Raya y Palma, 2009). En quinto lugar, las habilidades de entrada al léxico se encomiendan de la recuperación automática de las fonologías de palabras familiares, sin que se tenga que llevar a cabo un tiempo de reflexión explícito. En sexto lugar, los procesos de automatización suponen la automatización, propiamente dicha, de las reglas de conversión grafema-fonema. En penúltimo y séptimo lugar, los 
procesos fonológicos se refieren al incremento del conocimiento de los grafemas que se produce conforme se va progresando en la lectura, reconociendo los grafemas como unidades abstractas (Nunes y Bryant, 2006). Por último lugar, los procesos prosódicos, muestran su interés en el desarrollo y adquisición de la lectura y escritura, conociéndose también como fonología de tipo suprasegmental (Peterson y Pennington, 2012).

\section{2.-Vías de acceso a la lectura.}

En esta sección se lleva a cabo una descripción detallada de las dos vías de acceso a la lectura. Es de interés señalar, que en la lectura, las señales visuales se comportan como señales auditivas en los sistemas alfabéticos y silábicos, debido a que, la información ocular trasmite información fonológica y lingüística. Por tanto, los esquemas alfabéticos constituyen los fonemas de una lengua, dando lugar, a la posibilidad de representar todas las palabras y mensajes posibles como un conjunto de símbolos, siendo también necesario, conocer las correspondencias sonoras de cada símbolo del alfabeto para poder producir palabras. Así, para poder leer, el lector debe identificar y diferenciar entre los diversos símbolos visuales, aislados y en grupo, debe otorgar a cada símbolo un sonido, y mayormente, reconocer cada palabra como una configuración ortográfica significante, dándole una pronunciación. (Defior, Serrano y Gutiérrez, 2015). En adición a lo anterior, Dehaene (2011) sostiene, que para saber leer es suficiente reconocer el sonido que tiene cada letra; en la lectura, la mayoría de las palabras de una lengua, en nuestro caso, el español, pueden leerse mediante la conversión de los grafemas en fonemas. En efecto, el grado de dificultad para aprender a leer es diferente según la lengua.

Así bien, el modelo de la doble ruta propone la utilización de una vía directa, también llamada visual o léxica y de una vía indirecta, también conocida por fonológica 0 subléxica. En cuanto a la ruta visual o léxica, a juicio de Cuetos (2008), es usada cuando se entra de un modo directo al léxico visual que tiene cada sujeto, estando este formado por las representaciones ortográficas de las palabras que el individuo ha ido añadiendo durante su tiempo de experiencia con la lectura. El acceso a este tipo de "depósito" léxico, no supone necesariamente poder obtener el significado concreto de la palabra, sino todo lo contrario, esto es, conectar o enlazar con el sistema semántico. Es decir, el lector puede reconocer una palabra sin que verdaderamente conozca su significado. De este modo, este depósito organiza los conceptos en diversas categorías. Si la lectura se produce en voz alta, se tendrá que activar el léxico fonológico, formado por sus respectivas representaciones fonológicas, procediendo a la articulación de la palabra que se quiere leer. Por consiguiente, la ruta descrita está constituida por tres elementos: el léxico visual, el léxico fonológico y el sistema semántico. Sin embargo, aunque estos elementos difieren entre sí, interactúan paralelamente con la finalidad de conseguir acceder de forma rápida a la palabra como si de un todo se tratara.

Por su parte y atendiendo de nuevo a Cuetos (2008), la ruta fonológica o indirecta es aquella que permite al lector realizar una lectura de las palabras mediante la conversión gradual de las letras en sonidos, lo que se conoce como proceso de conversión grafema-fonema, del que ya hemos hablado anteriormente. Este proceso 
está conformado por diferentes sub-procesos. El primero, el análisis de los grafemas, en el que se separa los grafemas, el segundo, la asignación de los fonemas, cuya función es identificar los sonidos correspondientes a cada grafema; y el tercero, el acoplamiento de los fonemas, el cual permite que se produzca la articulación.

En relación a la ruta visual y la implicación de la misma con las funciones cerebrales, resulta de interés decir que, para poder interpretar las palabras escritas, una región del cerebro, más específicamente, la de la corteza visual, llamada área de la forma visual de las palabras, ejerce la función de almacenamiento de los conocimientos visuales que poseemos sobre las letras y sus múltiples combinaciones. La respuesta de esta área se incrementa a medida que se va mejorando en el aprendizaje de la lectura, en virtud de que las neuronas empiezan a especializarse con las letras y palabras más frecuentes en nuestro entorno y vocabulario.

Es síntesis, como apuntan Cohen y Dehaene (2004), aprender a leer es aprovechar una parte de la corteza visual, para que las neuronas que se encuentran allí, den sentido a las formas de las letras y por ende, a sus combinaciones.

\section{4.-Neurociencia de la lectura.}

\section{1.-Áreas cerebrales involucradas en la lectura.}

Es necesario especificar cómo es la organización del cerebro durante la lectura, haciendo especial hincapié en la identificación y localización de sistemas neuronales que se emplean para leer. Para la lectura, se requiere que muchas áreas cerebrales funcionen de forma conjunta mediante una compleja red de neuronas. Sin embargo, tiene que quedar claro, que no existe una región del cerebro que se dedique específicamente a la lectura, sino que el "sistema lector" se construye previamente sobre una serie de estructuras cerebrales. 0 sea, otros sistemas del cerebro operan de un modo conjunto con el propósito de poder crear un nuevo sistema funcional y conformar una función, siendo esta, la lectura (López-Escribano, 2009).

El desarrollo de la lectura, está condicionado por la coordinación de ciertos componentes presentes en el reconocimiento de las palabras, ortográfico, fonológico y semántico. Gracias a los avances llevados a cabo en neuroimágenes, se nos facilita una buena identificación del circuito lector. Ateniendo a Perfetti y Bolger (2004), manifiestan que este circuito lector incluye principalmente tres áreas cerebrales, localizadas en el hemisferio izquierdo del cerebro, en las que encontramos, (a) el área ventral (occipito-temporal), (b) el área dorsal, siendo esta un área tempo-parietal, correspondiéndose básicamente con la conocida área de Wernicke, y (c) el área frontal izquierda, en la que se incluye el área de Broca, el giro frontal inferior y el córtex insular. Igualmente, en el área ventral tienen lugar los procesos visuales y ortográficos, en el área dorsal o área de Wernicke acontece los procesos de decodificación y fonológicos, y en el área frontal o de área de Broca, tienen lugar los procesos articulatorios-fonológicos y semánticos.

Hruby y Goswami (2011) sugieren, por una parte, que los procesos sintácticos se encuentran asociados a una actividad en el giro frontal izquierdo o en el área de Broca. Por otra parte, los procesos semánticos se ubican en un área u otra dependiendo de si se encuentran o no a nivel de la palabra (temporal superior 
posterior y áreas parietales temporales; por ejemplo, el área de Wernicke y el giro supramarginal o surco temporal). A nivel de la oración, se sitúa en el área frontal izquierda, próxima al área de Broca, y a nivel de texto se encuentra en la zona del lóbulo frontal y parietal (p. 164).

\section{2.-La lectura en el cerebro.}

A posteriori, nos dirigimos a describir el camino que sigue la lectura en el cerebro. Por un lado, destacamos que la lectura requiere de la interacción de varias partes del cerebro, que al interrelacionarse forman un circuito cerebral. Dicho esto, sería incorrecto afirmar que este circuito cerebral del lenguaje escrito se asienta únicamente en el hemisferio izquierdo. En relación a lo cual, cabe subrayar que para una amplia mayoría de la población, alrededor de un $87 \%$, la lectura tiene predominancia en el hemisferio izquierdo; sin embargo, para un porcentaje pequeño, alrededor del $8 \%$, se ubica en el hemisferio derecho; para el resto, un $5 \%$, se distribuye tanto en un hemisferio como en el otro, sin que exista una definición clara (Narbona y Fernández, 1996). Por otro lado, el aprendizaje de la lectura produce cambios en el procesamiento cognitivo. Esto es, una vez que un niño aprende a leer, las áreas cerebrales que anteriormente eran utilizadas para procesar estímulos diferentes, pasan a ser parte de una nueva área especializada, el área de la forma visual de las palabras, de la que hablaremos más tarde. Por ello, esta reutilización es lo que se conoce como reciclaje neuronal (Muñoz, 2016).

En general, ya sabemos que la lectura no es igual en todos los individuos. Además de localizarse en un hemisferio u otro, ocurre lo mismo según el idioma, y es que los circuitos cerebrales que se activan, difieren en función de este último factor. De esta manera, en unos idiomas existe una relación sonido-letra, como es en nuestro caso, el castellano, donde hay una estimulación mayor en el área de Wernicke y en el giro angular, favoreciendo así la creación de nuevas palabras. En virtud de ello, Gabrieli, Christodoulou, O'Loughlin y Eddy (2010) indican que actualmente se conoce con precisión, que la región posterior izquierda del cerebro es la que se encarga de responder selectivamente a palabras y letras. Igualmente, para Dehaene (2009c), el aprendizaje lector consiste en la conexión de dos conjuntos de áreas cerebrales que se encuentran presentes desde edades tempranas: el sistema de reconocimiento de objetos (visual) y el circuito del lenguaje.

Así que, la lectura queda divida en una serie de fases de procesamiento de la información. En la fase inicial, el primer gran activador del circuito neuronal de la lectura es el visual, a partir de la reacción que se produce en la región occipital mediante la entrada visual de la palabra escrita. Sin que exista esfuerzo alguno, el cerebro humano tiene la habilidad del reconocer visualmente las palabras escritas gracias a una región cerebral específica para ello. Únicamente, el centro de la retina, conocido como fóvea (abarca aproximadamente el $15^{\circ}$ del campo visual), es la sección de la retina más útil para la lectura (Sere, Marendaz y Hérault, 2000). Seguidamente, una vez que la palabra ha entrado por la retina, es separada en múltiples porciones por las neuronas que existen en la retina. Porciones que se acoplan previamente para después decodificar los grafemas que la forman antes de reconocer la palabra. Por consiguiente, nuestro sistema visual es capaz de reducir la 
palabra que visualizamos al esqueleto que la conforma, obviando su tamaño o fuente, generando así un código estándar por palabra. Esta codificación suscita una jerarquización de la palabra, pasando de verla como un todo, a la producción de una descomposición de la misma, en morfemas, sílabas y grafemas.

Gracias las neuroimágenes, sabemos que en la región que se activa a causa de la entrada de un estímulo visual, la región occipito-temporal, se confirma la presencia de un área del sistema visual izquierdo del cerebro, que produce una alteración de la lectura de manera selectiva. Esta área tiene un rol esencial y específico en la lectura, y recibe el nombre de "caja de letras" del cerebro, siendo aquí donde comienza la segunda fase de la lectura en nuestro cerebro. Esta área se localiza en la misma zona cortical en todos los lectores y responde de una forma automática a las palabras escritas. Por un lado, las regiones posteriores del hemisferio izquierdo no tienen la función selectiva en la lectura. Por otro lado, las regiones (occipitales) están implicadas en los primeros periodos del análisis visual, sin ser específicas en la lectura, sino que ayudan al reconocimiento visual de una forma, objeto o color. De modo que, el área temporo-occipital de la llamada "caja de letras" discrimina la forma visual de las palabras. A posteriori, reparte esta información visual a diferentes regiones del hemisferio izquierdo, donde se codifica tanto el significado de las cadenas de letras y su sonido, a través de alguna de las dos rutas del lenguaje, como su articulación (Wolf, 2008).

En efecto, esta área de la forma visual de las palabras o caja de letras del cerebro, ejerce un rol crucial, ya que es la encargada de conectar la entrada visual con las redes del lenguaje, ejerciendo, así pues, de área de asociación. En atención a las dos redes cerebrales del lenguaje (la ruta fonológica y la ruta léxica), entran en juego de un modo paralelo, sin embargo, siguen un camino desigual en nuestro cerebro. Respecto a la ruta fonológica o indirecta, se dirige hacia el lóbulo temporal, en el que se efectúa la correspondiente conversión de los grafemas a fonemas. Los fonemas son analizados en el giro supramarginal para después generar su significación, seguido esto de la composición de la palabra en un todo, para en un último lugar articularla. Cabe decir, que esta ruta es usada para leer palabras nuevas y por tanto, para lectores aprendices. En cuanto a la ruta léxica o directa, es empleada para palabras que no descomponemos morfológicamente, sino que utilizamos de forma recurrente. Así pues, esta ruta conduce la señal visual hasta el giro supra temporal para dotar los grafemas de significado, sin necesidad de recurrir a una representación fonológica. Por otro lado, las relaciones semánticas ponen en funcionamiento a una nueva región, la corteza prefrontal interior izquierda, que generalmente se vincula con el pensamiento creativo (Hasson, Harel, Levy y Malach, 2003, p. 32).

En conclusión, en la lectura no existe un hemisferio dominante, leer implica un reciclaje neuronal y la involucración de una amplia red neuronal. Para Dehaene (2009b), leer, es entonces, desarrollar una conexión entre las áreas visuales y las áreas del lenguaje, siendo estas y todas las conexiones, bidireccionales. 


\section{3.-El tratamiento didáctico de la lectura desde la neurociencia.}

En esta última sección, prestamos especial atención a las diversas implicaciones que la neurociencia ha llevado a cabo en el aula en cuanto a la enseñanza de la lectura. En virtud de ello, Berninger y Richards (2002) describen una serie de prácticas educativas basadas en la neurociencia, que deben llevarse a cabo progresivamente según se va avanzando en el aprendizaje de la lectura. En primer lugar, hablamos de los programas de estimulación temprana. Sería adecuado aplicar estos programas en torno a los 18 meses, momento en el que las dendritas están aumentando en el hemisferio izquierdo y el lenguaje expresivo empieza a resurgir. Pues bien, durante este tiempo es fundamental conversar con los infantes y leerles cuentos, pese a que su capacidad expresiva sea baja. De este modo, es esencial estimular el lenguaje, ya que las áreas posteriores destinadas a la comprensión del lenguaje avanzan más rápidamente que las áreas frontales, enfocadas en la producción del mismo. Además, estos autores señalan que en la enseñanza de las letras y las palabras, es importante la creación de múltiples conexiones entre ellas, debido a que las diversas formas de las palabras se encuentran en áreas distintas del cerebro.

Los lectores principiantes mantienen la forma visual de las palabras a corto plazo en la memoria fonológica (Moats, 2004). Consecuentemente, la enseñanza de técnicas de autorregulación en la lectura permitirá una mayor maduración de los lóbulos frontales. Por tanto, la regulación de mano de un adulto, puede facilitar al lector pistas explícitas de cómo se lee, mediante instrucciones guiadas o andamiaje. Por otra parte, la lectura repetitiva de los textos provoca la automatización del reconocimiento de las palabras, y dicho proceso, se traslada a los circuitos que involucran el cerebelo (Santiuste y López-Escribano, 2005).

Respecto a los métodos de aprendizaje y enseñanza de la lectura, desde hace tiempo reinan dos, el fónico y el global. Existen controversias entre los beneficios e inconvenientes de uno $u$ otro. Por un lado, el método fónico tiene como objetivo enseñar intencionada y sistemáticamente la correspondencia grafema-fonema, permitiendo al niño leer cualquier palabra. Por otro lado, el método global, propone enseñar al lector el reconocimiento de las asociaciones directas que existen entre las palabras escritas y sus respectivos significados, sin llevar a cabo una decodificación fonológica. Este último método, da lugar a resultados muy limitados, sin embargo, muchos pedagogos lo defienden. Lebrero, Fernández-Pérez y García-García (2015) consideran, que la inmediatez de la lectura se aproxima a una ilusión provocada por la automaticidad de las etapas que la conforman, sin una percepción consciente. Lo que si es cierto, es que comprender y aprender el código de conversión grafemafonema es importante en el aprendizaje y enseñanza de la lectura. De este modo, nuestro cerebro reconoce las palabras separándolas en letras y grafemas, procesándose en paralelo en el área de la caja de letras del cerebro, situada en la corteza temporo-occipital izquierda. Por ello, Dehaene (2011) respalda que el método fónico es el más óptimo a la hora de enseñar a leer, debido a que la enseñanza sistemática de la correspondencia grafema-fonema ofrece un mejor rendimiento, teniendo mejores resultados en la comprensión de los textos gracias a la correcta e indispensable decodificación. Así pues, mientras más se automatiza las conversiones 
de grafemas a fonemas, más se concentra el lector en el significado de lo que está leyendo.

Las neuroimágenes develan, que en el cerebro de los niños disléxicos se produce un incremento en la activación de las regiones posteriores del hemisferio izquierdo. Por ello, se han propuesto programas de intervención educativa basados en el modelo del déficit fonológico, cuya principal finalidad radica en la estimulación de la conciencia fonológica de alumnos con este tipo de trastorno. De esta manera, Simos et al. (2002) afirman, que una vez que se ha completado con éxito esta intervención con programas fonológicos, acontecen variaciones significativas en los perfiles de activación cerebral en el alumnado que presenta dislexia, produciéndose mejoras en la decodificación lectora y mostrando importantes cambios en la activación de las áreas temporo-occipitales del hemisferio izquierdo, ahora sí, con una activación más propia de los estudiantes no disléxicos.

A modo de conclusión, destacar que los estudios del cerebro proporcionados por la neurociencia a la educación, muestran que las personas disléxicas, sobre todo, presentan dificultades en tareas de procesamiento auditivo, fonológico y visual. Por consiguiente, presentan una menor actividad en el hemisferio izquierdo del lóbulo temporo-occipital y parietal durante las tareas nombradas previamente (LópezEscribano, 2007).

\section{5.-Conclusión.}

En primer lugar, la neurociencia resulta ser una ciencia emergente y colaborativa, que tiene un interés principal en el estudio de la anatomía y comportamiento del cerebro humano. Por tanto, facilita el entendimiento de cómo el cerebro tiene la capacidad de producir la individualización de las acciones de un sujeto, y de este modo, aplicar parte de ello a explicar la forma de actuar de niños y niñas durante la etapa escolar.

En segundo lugar, la neuroeducación puede entenderse como oportunidad ideal para aprovechar los conocimientos arrojados por la neurociencia con el fin de optimizar el proceso de enseñanza y aprendizaje, teniendo como base, el funcionamiento cerebral de los estudiantes.

En tercer lugar, el aprendizaje de la lectura es una habilidad de carácter imprescindible y básico para el desarrollo de cualquier persona en una sociedad alfabetizada. Ahora bien, su adquisición es compleja y diversa en función de las necesidades del aprendiz. Además, su aprendizaje, que pasa por diversas etapas, requiere progresión, revisión y cautela, puesto que leer bien no solo depende de la velocidad, sino de una adecuada comprensión.

En último lugar, las aportaciones de la neurociencia en el tratamiento educativo de la lectura, resultan beneficiosas a la hora de atender a los estudiantes de acuerdo a sus características y necesidades individuales durante el aprendizaje de la lectura. Además, permite a los educadores conocer qué programas educativos son los más apropiados de aplicar en alumnos disléxicos, en función de aquellas áreas cerebrales en las que recaen este déficit lector, y de esta forma, apaliar las dificultades que estos lectores presentan. 
En definitiva, la neurociencia y los estudios de neuroimagen, nos desvelan las múltiples posibilidades del cerebro humano, holístico en funciones y en tareas tan dificultosas como es la lectura, donde las redes neuronales son capaces de englobar al mismo tiempo diversas estructuras, áreas y regiones cerebrales. Por ello, en un futuro cercano, la armonía entre la neurociencia y las ciencias educativas, sería enriquecedora para favorecer el desarrollo y acercamiento del comportamiento cerebral en tareas de aprendizaje.

\section{6.-Referencias.}

Blakemore, S., y Frith, U. (2011). Cómo aprende el cerebro. Las claves para la educación. Barcelona: Ariel.

Dehaene, S. (2009). Reading in the Brain: The Science and Evolution of a Human Invention. New York: Penguin. https://doi.org/10.1111/ijal.12055

Forés, A., y Ligioiz, M. (2011). Descubrir la neurodidáctica. Barcelona: Editorial UOC.

Hernández Fernández, A., y De Barros, C. (2015). Fundamentos para una educación inclusiva. Valencia: Olélibros.

Hruby, G., y Goswami, U. (2011). Neuroscience and reading: A review for reading education researchers. International Reading Association, 46(2), 156-172. https://doi.org/10.1598/RRQ.46.2.4

Lebrero, P., Fernández-Pérez, D., y García-García, E. (2015). Neurociencia de la lectura y la escritura. Fundamentos y estrategias didácticas. Madrid: Síntesis.

Mendoza, E., Murillo, G., y Maldonado, J. (2019). Las neurociencias y la marca personal del docente en el contexto educativo actual. Revista Órbita Pedagógica, 6(4), 157-166. doi: 0000-0003-1152-1672

Mora, F., y Sanguinetti, A. N. (2004). Diccionario de Neurociencia. Madrid: Alianza.

Paniagua, M. N. (2013). Neurodidáctica: Una nueva forma de hacer educación. Fides et Ratio, 6(6), 72-77. doi: 2071-081X

Wolf, M. (2008). Cómo aprendemos a leer: historia y ciencia del cerebro. Barcelona: Ediciones $\mathrm{B}$. 